\title{
A pesquisa sobre a disciplina Política Educacional no Brasil: situação e perspectivas ${ }^{1}$
}

\author{
Research on the Education Policy discipline in Brazil: \\ situation and perspectives \\ La investigación sobre la asignatura Política Educacional en Brasil: \\ situación y perspectivas \\ JEFFERSON MAINARDES \\ SILVANA STREMEL \\ GREGORY LUIS ROLIM ROSA
}

Resumo: $\mathrm{O}$ artigo apresenta aspectos históricos da disciplina Política Educacional no Brasil e uma análise da situação da pesquisa sobre essa disciplina nos Cursos de Pedagogia e outras Licenciaturas. O referencial teórico fundamentase no conceito de campo de Bourdieu. Trata-se de uma pesquisa de natureza bibliográfica, cuja metodologia envolveu o levantamento de trabalhos a respeito do tema. Argumenta que os estudos sobre o ensino de política educacional e a formação de pesquisadores para esse campo são relevantes para a compreensão do campo acadêmico da política educacional, bem como do desenvolvimento teórico do campo. O artigo indica uma série de perspectivas para a pesquisa sobre o ensino de política educacional na Graduação e na Pós-Graduação.

Palavras-chave: Política Educacional; licenciaturas; ensino.

Abstract: The paper presents historical aspects of the discipline Educational Policy in Brazil, and also an analysis of research situation on this discipline in the Pedagogy and other undergraduate courses. The theoretical background bases on Bourdieu's concept of field. It is a bibliographical research whose methodology involved the survey of works on the subject. It argues that the studies about the teaching of educational policy and the training of researchers in this field are relevant to the understanding of the academic field of educational policy as well as the theoretical development of this field. The article indicates a series of perspectives for the research on educational policy teaching in undergraduate and postgraduate studies.

Keyword: Educational Policy; licentiate degrees; teaching.

Resumen: El artículo presenta los aspectos históricos de la asignatura Política Educativa en Brasil y un análisis de la situación de la investigación sobre esta asignatura en los cursos de Pedagogía y otros profesorados. El marco teórico se basa en el concepto de campo de Bourdieu. Esta es una investigación de naturaleza bibliográfica, cuya metodología abarcó el revelamiento de trabajos sobre el tema. Argumenta que los estudios sobre la enseñanza de política 
educativa y la formación de investigadores para este campo son relevantes para la comprensión del campo académico de la política educativa, así como del desarrollo teórico de este campo. El artículo indica una serie de perspectivas para la investigación sobre la enseñanza de política educativa en la graduación y en el postgrado.

Palabras clave: Política Educativa; profesorado; enseñanza.

\section{INTRODUÇÃO}

O objetivo deste artigo é analisar a situação da pesquisa sobre a disciplina Política Educacional no Brasil, nos Cursos de Pedagogia e outras Licenciaturas. Em um primeiro momento, apresentamos breve histórico da disciplina Política Educacional no contexto da emergência e desenvolvimento da política educacional como campo acadêmico no Brasil. Em seguida, apresentamos uma síntese dos trabalhos de pesquisa sobre o tema. Nas considerações finais são apresentadas algumas perspectivas para a pesquisa sobre a temática.

$\mathrm{O}$ interesse em desenvolver pesquisas sobre o ensino de Política Educacional no Brasil é recente. Apenas nos últimos anos surgiram publicações sobre o tema, decorrente de pesquisas acadêmicas ou relatos de experiência sobre a disciplina. Os estudos localizados foram desenvolvidos a partir da criação do Núcleo de Investigação "Ensino de Política Educacional e Formação de pesquisadores do campo" no âmbito da ReLePe - Red de Estudios Teóricos y Epistemológicos en Política Educativa e da chamada de trabalhos do referido núcleo para o I Encuentro de Profesores de Politica Educativa, realizado em julho de 2015, na UNIFESP (Guarulhos-SP)'.

A ReLePe surgiu do interesse em ampliar as discussões de natureza teórico-epistemológica da pesquisa em política educacional. Partiu-se da constatação de que se trata de um campo abrangente, recente, em expansão e em construção, com diversas questões teórico-metodológicas e epistemológicas a serem aprofundadas, especialmente no contexto da América Latina. As temáticas pesquisadas e debatidas no âmbito da ReLePe contemplam diferentes aspectos da política educacional, tais como: problemas e limitações no desenvolvimento das pesquisas sobre política educacional; enfoques e perspectivas epistemológicas da pesquisa em política educacional; metodologias para a análise e pesquisa de políticas educacionais; história do campo da política educacional; investigação analítica de autores de referência em política educacional; produção do conhecimento

2 Informações sobre a ReLePe e os Anais do I Encuentro de Professores de Politica Educativa podem ser encontradas no site <www.relepe.org $>$. 
e tomadas de decisão em perspectiva epistemológica; epistemologia, política educacional e realidade latino-americana; ensino de política educacional e a formação de pesquisadores para esse campo.

O eixo de investigação "Ensino de política educacional e formação de pesquisadores para esse campo" reúne, até o presente, um reduzido número de pesquisas e publicações.

Neste artigo, consideramos que o estudo da disciplina Política Educacional é relevante, em primeiro lugar por marcar um dos momentos do processo da institucionalização da política educacional como campo acadêmico autônomo e específico. Além disso, é relevante examinar o quê (conteúdo) e o como (metodologias) do ensino de Política Educacional, na Graduação e na PósGraduação, pois são nesses espaços que ocorrem a formação de pesquisadores e a disseminação do desenvolvimento teórico construído pelos pesquisadores do campo.

\section{A DISCIPLINA POLÍTICA EDUCACIONAL NO CONTEXTO DO CAMPO DA POLÍTICA EDUCACIONAL}

Bourdieu postula a existência de muitos campos possíveis (político, religioso, intelectual, artístico, científico, etc.). Todo campo envolve um campo de forças, de lutas, as quais assumem características específicas em cada campo relativas à forma de capital em jogo e à posição que os agentes ocupam. Desse modo, a estrutura do campo é caracterizada como um estado de relação de força entre seus ocupantes, que têm em comum diversos interesses fundamentais ligados à própria existência do campo. Assim, a noção de campo representa um espaço de relações entre grupos que possuem diferentes posições nessa estrutura e é caracterizado por relações de conflito e disputas de poder. (BOURDIEU, 2003). Em termos analíticos, Bourdieu define um campo como:

\footnotetext{
Uma rede, ou configuração, de relações objetivas entre posições. Estas posições são objetivamente definidas, na sua existência e na determinação que impõem sobre seus ocupantes, agentes ou instituições, por sua situação atual e potencial (situs) na estrutura da distribuição de espécies de poder (ou capital) cuja posse comanda o acesso aos elementos específicos que estão em jogo no campo, bem como por sua relação objetiva com outras posições (dominação, subordinação homologia, etc.). (BOURDIEU; WACQUANT, 1992, p. 97, grifo do autor, tradução nossa) ${ }^{3}$.
} configuration, of objective relations between positions. These positions are objectively defined, in their existence and in the determinations they impose upon their occupants, agents or institutions, by their present and potential situation (situs) in the structure of the distribution of species of power (or capital) whose possession commands access to the specific profits that are at stake in the field, as well as by their objective relation to other positions (domination, subordination, homology, etc.)." 
Bourdieu (2003) faz uma analogia, comparando um campo a um jogo. Nesse sentido, cada campo funciona como um jogo em que as tomadas de posição dos seus ocupantes estão relacionadas às suas posições na estrutura do campo, ao habitus, aos capitais de que dispõem (econômico, cultural, simbólico, etc.), bem como aos propósitos que orientam suas ações, a conservação ou transformação da posição que ocupam no campo. É importante salientar que o habitus é tanto condição de funcionamento do campo como produto desse funcionamento (BOURDIEU, 2003). Assim, as ações dos indivíduos não são somente determinadas pelo campo, pois os agentes sociais “[...] não são partículas passivamente conduzidas pelas forças do campo [...]” (BOURDIEU, 2004a, p. 28). Ao mesmo tempo em que respondem às exigências do campo (às leis imanentes), há também possibilidade de que as ações sejam manifestadas levando em conta o habitus, isto é, as disposições adquiridas pelos agentes, que são "[...] maneiras de ser permanentes, duráveis que podem, em particular, levá-los a resistir, a oporse às forças do campo." (BOURDIEU, 2004a, p. 28). O sentido do jogo que Bourdieu menciona é justamente essa possibilidade dos agentes de tenderem às regras do campo, mas também desenvolverem estratégias de atuação orientadas pelo habitus. Logo, o sentido do jogo "[...] é o que permite gerar uma infinidade de 'lances' adaptados a infinidade de situações possíveis, que nenhuma regra, por mais complexa que seja, pode prever.” (BOURDIEU, 2004b, p. 21).

A partir de uma ampla pesquisa sobre a constituição do campo da política educacional no Brasil, fundamentada na teoria dos campos sociais de Bourdieu, consideramos que a emergência da política educacional como campo acadêmico específico ocorreu a partir da década de 1960, tendo como antecedentes os estudos sobre administração escolar, administração educacional e educação comparada (STREMEL, 2016, 2017; STREMEL; MAINARDES, 2013, 2016) ${ }^{4}$. Embora a década de 1960 possa ser considerada como início da emergência do campo em detrimento de uma série de aspectos como a criação da ANPAE, a implantação da Pós-Graduação no Brasil, o uso mais frequente da expressão "política(s) educacional(is)" em títulos de publicações brasileiras, um marco explícito no processo de institucionalização desse campo foi a criação do GT 5 - Estado e Política Educacional no âmbito da ANPEd (1986/1987). Como produto de condições históricas e sociais, a partir da década de 1990, o campo

\footnotetext{
4 Diversos autores brasileiros fazem menção à política educacional como "campo", com diferentes designações: campo de investigação (AZEVEDO; AGUIAR, 2001); campo acadêmico (SANTOS, 2008; STREMEL, 2016, 2017); campo das políticas educacionais (MAINARDES, 2009; KRAWCZYK, 2012; SANTOS; AZEVEDO, 2009, 2012; SOUZA, 2014, 2016; BELLO; JACOMINI; MINHOTO, 2014; MAINARDES, 2015; MAINARDES; TELLO, 2016; campo da pesquisa em política educacional (SANTOS; AZEVEDO, 2009, 2012; SCHNEIDER, 2014), campo teórico da política educacional (DIÓGENES, 2014). Uma síntese das designações utilizadas pelos autores é apresentada por Stremel (2016) e Sossai (2016).
} 
adquire maior autonomia e legitimação por meio da expansão de publicações sobre política educacional; da criação de disciplinas de/sobre política educacional; de departamentos; de linhas de pesquisa em Programas de Pós-Graduação em Educação (PPGEs); de grupos de pesquisa; de periódicos científicos especializados; de redes de pesquisa; da realização de eventos científicos específicos de política educacional (STREMEL, 2016).

A criação de uma disciplina específica constitui-se um dos momentos de institucionalização do campo. Com base em Gómez Campo e Tenti Fanfani (1989), Suasnábar e Palamidessi (2007), entendem que a criação de uma cátedra universitária ou de um departamento no âmbito estatal constituem momentos na institucionalização do campo que revelam "[...] o processo histórico de configuração e desenvolvimento de agências especializadas na produção, circulação e/ou validação de conhecimentos [...]." (p. 41, tradução nossa) $)^{5}$. De acordo com Suasnábar e Palamidessi (Ibidem), o grau de diferenciação e de especialização de saberes, de agentes, de instituições, de funções ou de divisões institucionais que expressa os momentos do campo pode ser analisado como "processos de institucionalização". Também, para Faria (2013), a "[...] institucionalização de um campo de estudos, de uma disciplina, vem tradicionalmente acompanhada da criação de associações profissionais, de conferências e de periódicos que influenciam, direta ou indiretamente, a alocação de recursos materiais e simbólicos" (p. 12).

A disciplina Política Educacional passou a ser incluída nos Cursos de Pedagogia e outras Licenciaturas, a partir da década de 1990, com designações diversas (p.ex. Política Educacional, Política e Gestão da Educação, Política e Organização da Educação, Política Educacional Brasileira, Políticas Públicas de Educação, entre outras). A emergência e o desenvolvimento da disciplina Política Educacional integra o desenvolvimento do próprio campo. Assim, surge como disciplina em virtude dos avanços do campo a partir da administração escolar e da educação comparada. No entanto, em algumas instituições, ela emerge como a tentativa de superar a visão jurídico-institucional da disciplina Estrutura e Funcionamento do Ensino.

No Brasil, o Curso de Pedagogia foi instituído por meio do Decreto-lei $\mathrm{n}^{\mathrm{o}} 1.190$, de 4 de abril de 1939, que estabeleceu as providências para a organização

5 A versão original desta citação é: “[...] el proceso histórico de configuración y desarrollo de agencias especializadas en la producción, circulación y/o validación de conocimientos [...].” 
da Faculdade Nacional de Filosofia, da Universidade do Brasil. Juntamente com o Curso de Pedagogia foi criada a cadeira de Administração Escolar e Educação Comparada ${ }^{6}$.

Costa, Muranaka e Borghi (2015) indicam que a inclusão da disciplina de Administração Escolar na Faculdade Nacional de Filosofia da Universidade do Brasil (1939) é considerada marco inicial da inserção dos conteúdos relacionados à Política Educacional nos cursos de formação de docentes. A disciplina, elaborada em um contexto histórico marcado por transformações no país, tinha como objetivo formar para a Administração Escolar, atendendo aos preceitos escolanovistas e fundamentada teoricamente na Teoria Geral da Administração.

Libâneo, Oliveira e Toschi (2012) explicam que, no Parecer 292/62, do Conselho Federal de Educação - CFE, e na resolução que fixava as matérias pedagógicas da licenciatura, constava a disciplina "Elementos de Administração Escolar", cujo objetivo era levar o licenciado a "conhecer a escola em que iria atuar, seus objetivos, sua estrutura e os principais aspectos de seu funcionamento, além de propiciar uma visão unitária do binômio escola-sociedade" (LIBÂNEO; OLIVEIRA; TOSCHI, 2012, p. 48).

No final da década de 1960, o Curso de Pedagogia passou por reformulações com o Parecer CFE n ${ }^{\circ}$ 252/69, que criou habilitações específicas, tendo em vista a formação de professores para o ensino normal e especialistas para as atividades de orientação educacional, supervisão escolar, administração escolar e inspeção escolar (SILVA, 1999). O curso passou a ter uma base comum e uma parte diversificada para as habilitações. Naquele contexto, a disciplina Administração Escolar e Educação Comparada deixou de fazer parte da base $\operatorname{comum}^{7}$ e foram incluídas as disciplinas Estrutura e Funcionamento do Ensino de $1^{\circ}$ Grau e Estrutura e Funcionamento do Ensino de $2^{\circ}$ Grau (LIBÂNEO; OLIVEIRA; TOSCHI, 2012). Paras as habilitações de Orientação Educacional, Supervisão Escolar, Administração Escolar e Inspeção Escolar, havia as disciplinas Estrutura e Funcionamento do Ensino de $1^{\circ}$ Grau e Estrutura e Funcionamento

\footnotetext{
6 A duração do Curso de Pedagogia foi estabelecida em três anos para a formação do bacharel. Em seguida, adicionando-se um ano de Didática, formava-se o licenciado. O curso organizou-se da seguinte maneira: $1^{\text {a }}$ série: Complementos de Matemática; História da Filosofia; Sociologia; Fundamentos Biológicos da Educação; Psicologia Educacional. $2^{a}$ série: Estatística Educacional; História da Educação; Fundamentos Sociológicos da Educação; Psicologia Educacional; Administração Escolar. $3^{a}$ série: História da Educação; Psicologia Educacional; Administração Escolar; Educação Comparada; Filosofia da Educação (SILVA, 1999).

$7 \quad$ A parte comum ficou composta pelas seguintes disciplinas: Sociologia Geral; Sociologia da Educação; Psicologia da Educação; História da Educação; Filosofia da Educação; Didática (SILVA, 1999).
} 
do Ensino de $2^{\circ} \mathrm{Grau}^{8}$. Com a aprovação da Lei no 5692/71, que instituiu o ensino de $1^{\circ}$ e $2^{\circ}$ graus, a denominação da disciplina alterou-se para "Estrutura e Funcionamento do Ensino de $1^{\circ}$ e $2^{\circ}$ Graus". (Idem, p. 49).

Para os Cursos de Pedagogia, a Resolução nº 2/1969 incluiu os temas sobre estrutura do ensino na parte diversificada do currículo sob três nomenclaturas: Estrutura e Funcionamento do Ensino de $1^{\circ}$ Grau, Estrutura e Funcionamento do Ensino de $2^{\circ}$ Grau e Estrutura e Funcionamento do Ensino Superior (Idem).

Saviani (1980) indica que o estudo da legislação do ensino era realizado, via de regra, na disciplina Estrutura e Funcionamento do Ensino, a qual assumia uma atitude formalista e acrítica, que predominava no desenvolvimento das programações dessa disciplina. Assim, a legislação acabava por se transformar numa "matéria árida, insipida, aversiva. Isto porque, limitando-se à apresentação e análise dos textos legais, tais programações acabam por enfatizar o ideal em detrimento do real, tomando o dever-ser pelo ser; a norma pelo fato" (p. 145). Contrariamente à tendência dominante, o autor mostrou que a legislação do ensino constitui um referencial privilegiado para a análise crítica da organização escolar.

Para Libâneo, Oliveira e Toschi (2012), a disciplina Estrutura e Funcionamento do Ensino ainda é ofertada e, de modo geral, os objetivos e conteúdos da disciplina assumem três abordagens bem distintas: a) predominantemente legalista, formalista e acrítica; b) predominantemente político-ideológica; e c) histórico-crítica.

$\mathrm{Na}$ abordagem legalista e formal, enfatizam-se os textos legais e os documentos, os quais são analisados sistêmica e funcionalmente. Na abordagem político-ideológica, enfatizam-se os chamados "textos críticos em detrimento dos textos legais e/ou documentos, sendo o real apresentado já em sua forma políticoideológica" (LIBÂNEO; OLIVEIRA; TOSCHI, 2012, p. 51). Na abordagem histórico-crítica, "parte-se dos textos legais e/ou documentos como referencial para a análise crítica do sistema de ensino e da organização escolar" (Ibidem). Os textos "críticos" servem "à reflexão e à análise crítica dos documentos da legislação, buscando captar seu espírito e seu contexto”. (Ibidem). Para Saviani (apud LIBÂNEO; OLIVEIRA; TOSCHI, 2012), nessa abordagem, os textos legais e/ou documentos são utilizados juntamente com os textos críticos para confrontar a situação proclamada (ideal) com a situação real. Desse modo, é possível captar as contradições objetivas e os fatores condicionantes da prática 
educativa, rompendo-se com a visão ingênua, acrítica, legalista, formal-idealista, reprodutora, parcializada e partidária do processo educativo e tornando o estudo mais fértil, dinâmico, investigativo e crítico-reflexivo (Idem, 2012, p. 52).

Libâneo, Oliveira e Toschi (2012) argumentam que houve uma evolução da disciplina, a qual passou da ênfase nos aspectos estruturais e formais do ensino para a ênfase nas questões de funcionamento da escola. A perspectiva legalista, descontextualizada e limitada foi "sendo modificada em favor da discussão de alternativas para a reconstrução da escola e do sistema educacional brasileiro (MENDONÇA; LELIS, 1988 apud LIBÂNEO; OLIVEIRA; TOSCHI, 2012, p. 53). Para os autores, “da visão sistêmica/tecnicista avançou-se para a visão histórico-crítica, em que as políticas para a educação em nível mundial, nacional, estadual e municipal são tratadas com maior intensidade” (Idem, p. 54).

Os autores consideram que o objeto da disciplina Estrutura e Funcionamento do Ensino, na atualidade, envolve o estudo das políticas educacionais, legislação educacional, análise sociopolítica dos documentos legais. Para eles, a disciplina deve

\footnotetext{
Assegurar, de forma competente, uma visão 'macro' e uma visão 'micro' da organização da educação escolar brasileira, a fim de ajudar os professores a conhecer melhor o sistema educacional e a organização escolar em suas relações. (Ibidem).
}

No processo de redemocratização do Brasil, nos anos de 1980 a 1990, bem como em virtude do movimento de reformulação dos cursos de formação de professores (década de 1980), a disciplina Estrutura e Funcionamento do Ensino sofreu alterações tanto em sua nomenclatura quanto em sua estrutura curricular. De acordo com Libâneo, Oliveira e Toschi (2012), surgiram disciplinas com designações diferentes, tais como: Educação Brasileira, Políticas Educacionais, Organização do Trabalho Pedagógico (ou Escolar), "cujo conteúdo disciplinar, todavia, foi pouco alterado em relação à Administração Escolar e à Estrutura e Funcionamento do Ensino" (LIBÂNEO; OLIVEIRA; TOSCHI, 2012, p. 49). Simultaneamente, a partir da década de 1980, o campo da Política Educacional firma-se como um campo acadêmico específico (STREMEL, 2016) e a disciplina Política Educacional passa a ser incluída nos currículos de Pedagogia e outras Licenciaturas a partir do final dos anos 1980 e início dos anos 1990. Atualmente, em diversas instituições de ensino superior, os conteúdos que, tradicionalmente, eram tratados na disciplina de Estrutura e Funcionamento do Ensino, têm sido incorporados na disciplina Política Educacional, com um enfoque mais contextualizado e não meramente jurídico-institucional. 


\section{PESQUISAS SOBRE A POLÍTICA EDUCACIONAL NOS CURSOS DE PEDAGOGIA E OUTRAS LICENCIATURAS}

Além do texto de Libâneo, Oliveira e Toschi (2012), que apresenta algumas informações sobre a disciplina Política Educacional no contexto da discussão sobre a disciplina Estrutura e Funcionamento do Ensino, e do artigo de Tello (2015), localizamos dez trabalhos apresentados no evento I Encuentro Latinomericano de Profesores de Politica Educativa (ReLePe), realizado em julho de 2015, na Unifesp (Guarulhos - SP). Desses dez trabalhos, quatro referem-se ao contexto brasileiro (COSTA; MURANAKA; BORGHI, 2015; FLACH; MASSON, 2015; MENDES, 2015; STREMEL; MAINARDES, 2015a); três no contexto argentino (ROMERO; GARCÍA, 2015; MARTIGNONI, 2015; VISACOVSKY, 2015); dois mexicanos (QUIANÉ; LÓPEZ, 2015; BONALS; ARENS; TRUJILO, 2015) e um estudo comparativo entre Brasil e Argentina (PRONKO, 2015). Os estudos de Flach e Masson (2014); Stremel e Mainardes (2015b) e Pronko (2016) foram publicados em periódicos, com revisões, posteriormente ao evento,

Tello (2015) considera que o forte impulso da perspectiva jurídicoinstitucional e os enfoques de planejamento que estavam presentes nas origens do campo da política educacional na América Latina e as perspectivas unicausais estão ainda presentes na formação dos jovens pesquisadores, com matrizes de elevado nível descritivo que se converte na tendência descritiva nos resultados das pesquisas. Tello (2015) considera que, desde o início, o campo da política educacional surge como campo eminentemente profissional e, assim, o profissional de política educacional deveria intervir de modo constante sobre a realidade. Isso levou a "priorizar o cenário de intervenção do profissional em detrimento do aprofundamento teórico, analítico e epistemológico dos instrumentos para pensar a realidade" (TELLO, 2015, p. 126). Para o autor, o surgimento de cátedras de Política Educacional marcam a institucionalização desse campo e isso deve ser compreendido no contexto do surgimento de novos currículos de ciências da educação na América Latina, com a sistematização para o ensino e pesquisa em suas diversas versões: Política Educacional, Política e Legislação Escolar, Política e Educação Comparada, Política e Organização Escolar e Política e Administração da Educação, no período de 1950-1970.

De acordo com as concepções da época, no período 1950-1970, as cátedras de Política Educacional surgiram com a preocupação em formar graduados em Pedagogia ou Ciências da Educação para o planejamento, compreensão da legislação escolar, políticas de universalização da educação primária e secundária. Para Tello (2015), a primeira etapa (até 1960) foi denominada enfoque jurídicoinstitucional, caracterizada pela análise da normativa legal. Na segunda etapa, a 
partir dos anos 1960, a política educativa esteve fortemente vinculada à teoria do planejamento e planejamento educacional, com o auge do desenvolvimentismo e da teoria do capital humano na América Latina. A terceira etapa, do fim da década de 1960 e durante a década de 1970, foi denominada de perspectiva crítica, com o surgimento de visões e enfoques crítico-reprodutivistas, que começam a questionar o funcionamento dos sistemas educativos nacionais, dando lugar aos estudos de etnografia educativa nas políticas educacionais, desenvolvimento da sociologia política crítica e perspectivas neomarxistas e pós-estruturalistas (TELLO, 2015). $\mathrm{O}$ autor considera que a realidade das ciências sociais e políticas, em particular a política educacional, requer uma transformação epistemológica que permita construir novas epistemologias para repensá-la a partir do atrevimento científico, que, de algum modo, desmorone e sacuda as perspectivas epistemológicas atuais, o qual permitirá, a partir dessa desconstrução, um espaço para iniciar um novo caminho epistemológico na América Latina.

\section{UMA BREVE SÍNTESE DOS TRABALHOS SOBRE A DISCIPLINA POLÍTICA EDUCACIONAL NO BRASIL}

Costa, Muranaka e Borghi (2015), com base no referencial teóricometodológico do materialismo histórico e dialético e por meio da análise de documentos curriculares, buscam situar a disciplina Política Educacional Brasileira (PEB) e Política e Organização da Educação Básica Brasileira (POEB) nos currículos das licenciaturas da Universidade Estadual Paulista - Unesp (Rio Claro). As autoras apresentam um histórico da disciplina Política Educacional Brasileira nos cursos de licenciatura, apontando que, a partir de 2002, com a criação das Diretrizes Curriculares Nacionais para a Formação de Professores da Educação Básica, o conhecimento sobre as dimensões cultural, social, política e econômica da educação é considerado integrante do conjunto de conhecimentos exigidos para a formação docente. Nesse sentido, surgiu a tendência de empregar as denominações Política Educacional (PE), Política Educacional Brasileira (PEB) ou Política e Organização da Educação Básica Brasileira (POEB) para a disciplina. As autoras consideram que a disciplina de PEB é o espaço propício para a formação política dos alunos por levá-los a uma visão contextualizada da realidade e da relação entre escola, sociedade e gênese da sociedade capitalista. As autoras concluíram que 
Se trata de uma disciplina cada vez mais necessária, pois se configura como um espaço privilegiado de discussão política, especialmente em licenciaturas das áreas de Ciências Exatas e Biológicas, e consideramos insuficiente sua integração com as matérias que não integram o campo de saber específico dessas áreas. (COSTA; MURANAKA; BORGHI, 2015, p. 2).

No texto "A disciplina de Política Educacional em cursos de formação de professores", Flach e Masson (2014, 2015) apresentam a importância da disciplina Política Educacional na formação de professores. As autoras analisam a organização dos conhecimentos da referida disciplina em diferentes currículos em uma instituição de ensino superior do Paraná, utilizando-se do materialismo histórico e dialético como suporte teórico. As autoras elencam que alguns conteúdos são necessários para o estudo da disciplina, como: a) o estudo das características fundamentais da sociedade capitalista: luta de classes, relações sociais de produção, antagonismo entre capital e trabalho; b) o estudo do papel do Estado na definição das políticas educacionais; c) o campo da política educacional; d) a organização da educação escolar; e e) aspectos legais da educação brasileira.

A partir de uma análise documental das ementas das disciplinas da área de Política Educacional nos cursos de formação de professores da universidade pesquisada, Flach e Masson $(2014,2015)$ observaram, por meio das nomenclaturas e carga horária, que a disciplina tem como alicerce o ensino de caráter jurídiconormativo, em relação à sociedade e à organização escolar. Sendo o professor responsável pela organização dos conteúdos da disciplina, as autoras indicam que a maioria dos docentes não possuem produção científica na área de políticas educacionais, o que acarreta a fragilização do ensino e da formação discente.

Flach e Masson (2014, 2015) reconhecem a importância dos conhecimentos da disciplina de Política Educacional para a formação de professores, mas apontam que "a área se fragiliza em razão da descontinuidade do trabalho desenvolvido pelos professores responsáveis pelas disciplinas devido a contratos de trabalho precário e da não vinculação com pesquisa do campo da política educacional" (FLACH; MASSON, 2015, p. 16).

No trabalho de Mendes (2015), percebe-se a importância de se reconhecer a visão do aluno em relação aos conteúdos que são lecionados na disciplina Política Educacional. A autora realiza um levantamento importante considerando a formação política do estudante na Educação Básica e seu envolvimento em movimentos estudantis. Caracteriza, por meio de questionários, as expectativas dos alunos a respeito do papel da disciplina em seu processo de formação no Ensino Superior. Analisa a disciplina Educação Brasileira e Organização das Políticas Públicas (EBOPP) de uma universidade federal. Por meio do estudo de caso e aplicação de questionários, a pesquisa teve como finalidade apresentar 
a posição dos alunos em relação ao nível de interesse pelas questões políticas, o envolvimento político dos alunos durante sua formação e a visão deles sobre a importância da disciplina no processo de formação docente. Em relação ao interesse pelas questões políticas, a pesquisa apontou que a maioria dos entrevistados afirma ter interesse, pois proporciona a formação cidadã, apreensão das questões legais e das determinações do Estado e da sociedade na educação. Além disso, citam a importância de espaços para debate e discussão das questões políticas. A disciplina de EBOPP, com carga horária de 68 horas e componente curricular obrigatório nos cursos de Licenciatura, tem relevância reconhecida pelos estudantes em seu processo de formação, vez que possibilita a análise das políticas educacionais, da função do Estado, do aparato legal e a compreensão da realidade em que estão inseridos. Consideram em grau de importância que a Lei de Diretrizes e Bases da Educação Nacional (LDB ou LDBEN) e a Constituição Federal são os conteúdos que melhor assimilam e possuem maior relevância para sua formação. Muitos acadêmicos apontam que a carga horária da disciplina é insuficiente para melhor aproveitamento. A disciplina é essencial, na visão dos alunos, para a sua formação como docente, propiciando conhecimentos para a compreensão do funcionamento do Estado e suas relações com a educação.

No trabalho "Reflexões iniciais sobre a disciplina Política Educacional em cursos de Pedagogia no Brasil", Stremel e Mainardes (2015a, 2015b) analisam o currículo de Cursos de Pedagogia em 70 universidades brasileiras, com o objetivo de apresentar a estrutura curricular da disciplina Política Educacional e seus componentes curriculares (designações, carga horária e conteúdos). Em relação à denominação da disciplina, constataram que uma diversidade de designações é empregada, o que indica certa dispersão do campo, pois os termos "Política Educacional" ou "Políticas Educacionais" e, ainda, "Política e gestão da educação" são termos mais comumente utilizados para referir-se a esse campo. Com relação à carga horária, observa-se que, na maioria das instituições, a disciplina relacionada à Política Educacional possui 60 horas/aula. A análise das ementas indicou que os conteúdos tradicionalmente tratados estão relacionados à organização da educação brasileira, aspectos legais, financiamento e gestão da educação, com pouca representatividade de conteúdos que expressem os aspectos teóricos, epistemológicos, de metodologias e abordagens de pesquisa no campo da política educacional. A análise de programas da disciplina permitiu identificar que a maior parte das referências é de livros.

Pronko (2015) relata sua experiência como docente no Ensino Superior na área de políticas públicas em instituições brasileiras e argentinas. A autora apresenta as dificuldades constatadas nos trabalhos finais de disciplina. Os principais problemas indicados são os seguintes: problemas gerais que advêm 
de má formação na Educação Básica, insuficiente aproveitamento das leituras indicadas, baixa qualidade da escrita e desconhecimento das normas específicas do trabalho acadêmico. Segundo a autora, ao adentrarem os espaços de formação em nível de Graduação e Pós-Graduação, os alunos apresentam conhecimentos superficiais em relação a perspectiva teórico-metodológica, o que causa dificuldades de compreensão. Tais dificuldades expressam-se nas discussões propostas pela disciplina, nas quais, na maioria das vezes, os alunos embasam seus argumentos em conhecimentos de senso comum, não possibilitando relação dialógica com estudiosos e teorias do campo.

Para a autora, os problemas específicos estão "ligados às dificuldades de apreensão das bases conceituais do materialismo histórico, concepção teóricometodológica que orienta a organização dessas disciplinas" (PRONKO, 2016, p. 1). Ela apresenta-os a partir de quatro eixos. O primeiro eixo é a história sem sujeito e mito do eterno progresso, ou seja, a dificuldade dos alunos em reconhecerem o papel da ação humana como agente político e transformador da realidade. O segundo eixo apresenta-se na concepção dos alunos de que as políticas são resultados dos estudos de grandes pensadores em um mundo movido pelas ideias das quais resultam as políticas. Outra característica apontada como terceiro eixo problemático é o fato de os alunos determinarem o Estado como sujeito autônomo e a sociedade como separada por esferas, o que leva ao quarto eixo problemático: a educação como esfera isolada da realidade (PRONKO, 2015, 2016).

\section{CONSIDERAÇÕES FINAIS}

Neste artigo, apresentamos um breve histórico da disciplina Política Educacional no Brasil e da situação da pesquisa sobre essa disciplina no Curso de Pedagogia e nas demais Licenciaturas. Trata-se de um foco bastante específico dentro de um conjunto de questões que podem ser exploradas. Demonstramos que são ainda escassas as pesquisas sobre esse tema. Assim, há diversos aspectos a serem explorados, tais como: aspectos históricos da disciplina Política Educacional nos cursos de formação de professores; designações utilizadas pelas Instituições; carga horária; análise de ementas, de planos de ensino (programas), de bibliografias;

perfil dos docentes; opinião de alunos; análise de livros de natureza didática da 
disciplina"; estudos comparativos da disciplina em diferentes países, etc. Com relação aos aspectos históricos, seria relevante desenvolver mais estudos sobre as concepções e os conteúdos que constituíram o ensino de Administração Escolar e Educação Comparada, que estão na origem do que denominamos atualmente como política educacional.

Consideramos que as pesquisas sobre o ensino de Política Educacional vão muito além dessa disciplina ou de correlatas nos cursos de formação de professores. Abrangem outras atividades na Graduação e Pós-Graduação, tais como: produções nas Linhas de Pesquisa de PPGEs; atividades dos grupos de pesquisa; seminários, eventos, sessões de orientação; minicursos e outras atividades formativas.

Em nossa perspectiva, os estudos sobre o ensino de Política Educacional e a formação de pesquisadores para esse campo integram as pesquisas sobre o processo de constituição e desenvolvimento do campo acadêmico da política educacional. As pesquisas sobre esse campo abrangem: a) estudos históricos sobre a constituição do campo ${ }^{10}$; b) estudos sobre a produção do conhecimento em política educacional ${ }^{11}$; c) aspectos da organização do ensino e da formação de pesquisadores na Pós-Graduação; d) expansão do campo; e) ensino de Política Educacional; e f) a formação de pesquisadores para esse campo. Os estudos sobre essas questões são relevantes na medida em que permitem a compreensão sobre o desenvolvimento teórico do campo, das abordagens teórico-epistemológicas empregadas, das tendências no ensino e na pesquisa. É importante destacar que essas temáticas estão inter-relacionadas e não precisam ser tratadas isoladamente.

9 Stremel (2016) menciona os seguintes livros que podem ser considerados de natureza didática para o ensino da política educacional nos cursos de Graduação: Martins (1993); Azevedo (1997); Shiroma, Moraes e Evangelista (2000); Vieira e Albuquerque (2001); Libâneo, Oliveira e Toschi (2012); Vieira e Farias (2007); Ney (2008); Kfouri (2009); Vieira (2009); Bruel (2010); Souza, Gouveia e Tavares (2011); Santos (2012); Carvalho (2012).

Por exemplo, Stremel (2016, 2017); Santos (2008, 2014).

10

Por exemplo, Stremel (2016, 2017); Santos (2008, 2014).

11 O estudo sobre a produção do conhecimento em política educacional é amplo e pode incluir: a) análise da situação do campo e de sua expansão; análise teórico-epistemológica das produções e publicações (metapesquisa); o espaço da pesquisa em política educacional na Pós-Graduação; análise das estratégias utilizadas pelos PPGEs e pelos pesquisadores no desenvolvimento das pesquisas; estudo de grupos e linhas de pesquisa; redes de pesquisa; etc. No contexto brasileiro, tais temáticas tiveram um desenvolvimento significativo nos últimos anos. Ver, por exemplo, Witmann e Gracindo (2001), Azevedo e Aguiar (2001), Pereira e Andrade (2005), Maia (2008), Santos (2008), Santos e Azevedo (2009), Mainardes; Ferreira e Tello (2011); Arosa (2013), Souza (2014), Krawczyk (2015), Tello e Mainardes (2015, 2016), Silva e Jacomini (2016), entre outros. 


\section{REFERÊNCIAS}

AROSA, A. de C. C. A produção acadêmico-científica sobre política educacional no GT 5 da ANPEd (2000 a 2009). 2013. 264 f. Tese (Doutorado em Educação) - Universidade Federal do Rio de Janeiro, Rio de Janeiro, 2013.

AZEVEDO, J. M. L. de. A educação como política pública. São Paulo: Autores Associados, 1997.

AZEVEDO, J. M. L. de; AGUIAR, M. A. A produção do conhecimento sobre a política educacional no Brasil: um olhar a partir da ANPED. Educação \& Sociedade, Campinas, v. 22, n. 77, p. 49-70, set./dez. 2001.

BELlO, I. M.; JACOMINI, M. A.; MINHOTO, M. A. P. Pesquisa em política educacional no Brasil (2000-2010): uma análise de teses e dissertações. Práxis Educativa, Ponta Grossa, v. 9, n. 2, p. 369-393, jul./dez. 2014.

BONALS, L.P.; ARENS, A. G. L.; TRUJILO, A. R. P. La política educativa: un componente necesario en la formación de docentes que investigan sobre su práctica. In: ENCUENTRO LATINOAMERICANO DE PROFESSORES DE POLÍTICA EDUCATIVA, 1., 2015, Guarulhos-SP. Anais... Guarulhos-SP: UNIFESP, 2015. p.1-21

BOURDIEU, P. Os usos sociais da ciência: por uma sociologia clínica do campo científico. Tradução de Denice Barbara Catani. São Paulo: Editora UNESP, 2004a.

BOURDiEU, P. Coisas ditas. Trad. Cássia R. da Silveira e Denise Moreno Pegorim. 1. reimp. da 1. ed. São Paulo: Brasiliense, 2004b.

BOURDIEU, P. Questões de sociologia. Trad. Miguel Serras Pereira. Lisboa: Fim de Século, 2003.

BOURDIEU, P.; WACQUANT, L. J. D. An invitation to reflexive sociology. Chicago: The University of Chicago Press, 1992.

BRUEL, A. L. de O. Políticas e legislação da educação básica no Brasil. Curitiba: Ibpex, 2010. 
CARVAlHO, E. J. G. de. Políticas públicas e gestão da educação no Brasil. Maringá: EDUEM, 2012.

COSTA, A. de C.; MURANAKA, M. A. S.; BORGHI, R. F. A contribuição da disciplina PEB à formação de professores do ensino básico: estudo do caso das licenciaturas em uma Universidade Estadual. In: ENCUENTRO LATINOAMERICANO DE PROFESSORES DE POLÍTICA EDUCATIVA, 1., 2015, Guarulhos-SP. Anais... Guarulhos-SP: UNIFESP, 2015. p.1-24.

DIÓGENES, E. M. N. Análise das bases epistemológicas do campo teórico da política educacional. Práxis Educativa, Ponta Grossa, v. 9, n. 2, p. 333-353, jul./ dez. 2014.

FARIA, C. A. P. de. A multidisciplinaridade no estudo das políticas públicas. In: MARQUES, E.; FARIA, C. A. P. de. (Orgs.). A política pública como campo multidisciplinar. São Paulo: Editora Unesp; Rio de Janeiro: Editora Fiocruz, 2013. p. 11-21.

FLACH, S.; MASSON, G. A disciplina de Política Educacional em cursos de formação de professores. Revista Pedagógica, Chapecó, v. 15, n. 33, p.181-199, 2014.

FLACH, S.; MASSON, G. A disciplina de Política Educacional em cursos de formação de professores. In: ENCUENTRO LATINOAMERICANO DE PROFESSORES DE POLÍTICA EDUCATIVA, 1., 2015, Guarulhos-SP. Anais... Guarulhos-SP: UNIFESP, 2015. p. 1-18.

GÓMEZ CAMPO, V. M.; TENTI FANFANI, E. Universidad y profesiones: crisis y alternativas. Buenos Aires: Miño y Dávila Editores, 1989.

KFOURI, S. F. Políticas educacionais: estruturas e sistemas. São Paulo: Pearson Education do Brasil, 2009.

KRAWCZYK, N. R. Pesquisa e formação em política educacional: um desafio interdisciplinar. Revista Olh@res, Guarulhos, v. 3, n. 2, p. 8-14, nov. 2015.

KRAWCZYK, N. A historicidade da pesquisa em política educacional: o caso do Brasil. Jornal de Políticas Educacionais, Curitiba, v. 6, n. 12, p. 3-11, jul./dez. 2012. 
LIBÂNEO, J. C.; OLIVEIRA, J. F. de; TOSCHI, M. S. Educação escolar: políticas, estrutura e organização. 10. ed. São Paulo: Cortez, 2012.

MAIA, G. Z. A. As publicações da ANPAE e a trajetória do conhecimento em administração da educação no Brasil. Revista Brasileira de Política e Administração da Educação, Porto Alegre, v. 24, n. 1, p. 31-50, jan./abr. 2008.

MAINARDES, J. Reflexiones sobre el objeto de estudio de la política educativa. In: TELLO, C. (Comp.). Los objetos de estudios de la política educativa: hacia una caracterización del campo teórico. Ciudad Autónoma de Buenos Aires: Autores de Argentina, 2015. p. 25-42.

MAINARDES, J. Análise de políticas educacionais: breves considerações teóricometodológicas. Contrapontos, Itajaí, v. 9, n. 1, p. 4-16, jan./abr. 2009.

MAINARDES, J.; TELLO, C. A pesquisa no campo da política educacional: explorando diferentes níveis de abordagem e abstração. Archivos Analíticos de Políticas Educativas, v. 24, n. 75, p. 1-18, jul. 2016.

MAINARDES, J.; FERREIRA, M. S.;TELLO, C. Análise de políticas: fundamentos e principais debates teórico-metodológicos. In: BALL, S. J.; MAINARDES, J. (Orgs.). Políticas educacionais: questões e dilemas. São Paulo: Cortez, 2011. p. 143-172.

MARTIGNONI, L. La enseñanza de la política educativa en la formación docente el caso de la carrera de Geografía. In: ENCUENTRO LATINOAMERICANO DE PROFESSORES DE POLÍTICA EDUCATIVA, 1., 2015, Guarulhos-SP. Anais... Guarulhos-SP: UNIFESP, 2015. p. 1-13.

MARTINS, C. O que é política educacional. São Paulo: Brasiliense, 1993.

MENDES, V. O estudo da política educacional nos cursos de licenciatura de uma instituição federal de ensino superior. In: ENCUENTRO LATINOAMERICANO DE PROFESSORES DE POLÍTICA EDUCATIVA, 1, 2015, Guarulhos-SP. Anais... Guarulhos-SP: UNIFESP, 2015. p. 1-21.

NEY, A. Política educacional: organização e estrutura da educação brasileira. Rio de Janeiro: WAK Editora, 2008. 
PEREIRA, G. R. de M.; ANDRADE, M. da C. L. de. A construção da administração da educação na RBAE (1983-1996). Educação \& Sociedade, Campinas, v. 26, n. 93, p. 1393-1411, set./dez. 2005.

PRONKO, M. A. Desafios teórico-metodológicos para o ensino de políticas educacionais na perspectiva do materialismo histórico. Revista de Estudios Teóricos y Epistemológicos en Política Educativa, v. 1, n. 2, p. 1-17, jul./ dez. 2016.

PRONKO, M. A. Desafios teórico-metodológicos para o ensino de políticas educacionais na perspectiva do materialismo histórico. In: ENCUENTRO LATINOAMERICANO DE PROFESSORES DE POLÍTICA EDUCATIVA, 1., 2015, Guarulhos-SP. Anais... Guarulhos-SP: UNIFESP, 2015. p. 1-17.

QUIANÉ, L. M. J.; LÓPEZ, V. M. S. El estudio de la política educativa en la maestría en educación básica de la universidad pedagógica nacional-México: un relato reflexivo y crítico desde sus origenes, diseño y operación. In: ENCUENTRO LATINOAMERICANO DE PROFESSORES DE POLÍTICA EDUCATIVA, 1., 2015, Guarulhos-SP. Anais... Guarulhos-SP: UNIFESP, 2015. p. 1-19.

ROMERO, S. A.; GARCÍA, M. G. Sentidos y desafíos de enseñar política educativa en la formación docente. In: ENCUENTRO LATINOAMERICANO DE PROFESSORES DE POLÍTICA EDUCATIVA, 1., 2015, Guarulhos-SP. Anais... Guarulhos-SP: UNIFESP, 2015. p. 1-15.

SANTOS, A. L. F. dos. A Pós-Graduação em Educação e o tratamento do tema política educacional: uma análise da produção do conhecimento no Nordeste do Brasil. 2008. 270 f. Tese (Doutorado em Educação) - Universidade Federal de Pernambuco, Recife, 2008.

SANTOS, A. L. F. dos. Conhecimento e interesse: analisando fatores que influenciam a constituição do campo acadêmico da pesquisa sobre política educacional. Revista Brasileira de Política e Administração da Educação, Porto Alegre, v. 30, n. 1, p. 161-180, jan./abr. 2014. 
SANTOS, A. L. F. dos; AZEVEDO, J. M. L. de. Regulação e legitimação da pesquisa sobre a política educacional como campo acadêmico: um estudo a partir dos programas de Pós-Graduação do Nordeste brasileiro. In: GOMES, A. M.; OLIVEIRA, J. F. de (Orgs.). Reconfiguração do campo da educação superior. Campinas: Mercado de Letras, 2012. p. 71-93. (Série Estudos em Políticas Públicas e Educação).

SANTOS, A. L. F. dos; AZEVEDO, J. M. L. de. A Pós-Graduação no Brasil, a pesquisa em educação e os estudos sobre a política educacional: os contornos da constituição de um campo acadêmico. Revista Brasileira de Educação, Rio de Janeiro, v. 14, n. 42, p. 534-550, set./dez. 2009.

SANTOS, P. S. M. B. dos. Guia prático da política educacional no Brasil: ações, planos, programas e impactos. São Paulo: Cengage Learning, 2012.

SAVIANI, D. Análise crítica da organização escolar brasileira por meio das leis no 5.540/68 e 5.692/71. In: SAVIANI, D. Educação: do senso comum à consciência filosófica. São Paulo: Cortez Editora; Autores Associados, 1980. p. 133-155.

SCHNEIDER, M. P. Pesquisa em política educacional: desafios na consolidação de um campo. Revista Educação (PUC-Campinas), Campinas, v. 19, n. 1, p. 5-13, jan./abr. 2014.

SHIROMA, E. O.; MORAES, M. C. M. de; EVANGELISTA, O. Política educacional. Rio de Janeiro: DP\&A Editora, 2000.

SILVA, A. A.; JACOMINI, M. A. (Orgs.). Pesquisa em políticas educacionais: características e tendências. Feira de Santana: UEFS Editora, 2016.

SILVA, C. S. B. da. Curso de Pedagogia no Brasil: história e identidade. Campinas: Autores Associados, 1999.

SOSSAI, F. C. Anotações sobre o conceito de campo e os estudos em políticas educacionais. Revista de Estudios Teóricos y Epistemológicos en Política Educativa, v. 1, n. 2, p. 294-333, jul./dez. 2016.

SOUZA, A. R. de. A política educacional e seus objetos de estudo. Revista de Estudios Teóricos y Epistemológicos en Política Educativa, v. 1, n. 1, jan./ jun, p. 75-89, 2016. 
SOUZA, A. R. de. A pesquisa em políticas educacionais no Brasil: de que estamos tratando? Práxis Educativa, Ponta Grossa, v. 9, n. 2, p. 355-367, jul./dez. 2014.

SOUZA, A. R. de; GOUVEIA, A. B.; TAVAres, T. M. (Orgs.). Políticas educacionais: conceitos e debates. Curitiba: Appris, 2011.

STREMEL, S. Aspectos teórico-metodológicos para a análise da constituição do campo acadêmico da política educacional no Brasil. Revista de Estudios Teóricos y Epistemológicos en Política Educativa, v. 2, n. 1, p. 1 - 19, enero/ jun. 2017.

STREMEL, S. A constituição do campo acadêmico da política educacional no Brasil. 2016. 312 f. Tese (Doutorado em Educação) - Universidade Estadual de Ponta Grossa, Ponta Grossa, 2016.

STREMEL, S.; MAINARDES, J. A emergência do campo da política educacional em diferentes países. Tópicos Educacionais, Recife, v. 22, n. 1, p. 115-138, jan./ jul. 2016.

STREMEL, S.; MAINARDES, J. Reflexões iniciais sobre a disciplina política educacional em cursos de pedagogia no Brasil. In: ENCUENTRO LATINOAMERICANO DE PROFESSORES DE POLÍTICA EDUCATIVA, 1, 2015, Guarulhos-SP. Anais... Guarulhos-SP: UNIFESP, 2015a. p. 1-25.

STREMEL, S.; MAINARDES, J. A disciplina Política Educacional em Cursos de Pedagogia no Brasil: primeiras aproximações. Jornal de Políticas Educacionais, Curitiba, v. 9, n. 17-18, p. 137-155, 2015b.

STREMEL, S.; MAINARDES, J. A constituição do campo da política educacional no Brasil: notas sobre a periodização. VII SIMPÓSIO INTERNACIONAL O ESTADO E AS POLÍTICAS EDUCACIONAIS NO TEMPO PRESENTE. Anais... Uberlândia, 2013.

SUASNÁBAR, C.; PALAMIDESSI, M. Notas para una historia del campo de producción de conocimientos sobre educación en la Argentina. In: PALAMIDESSI, M; SUASNÁBAR, C.; GALARZA, D. (Comps.). Educación, conocimiento y política: Argentina, 1983-2003. Buenos Aires: Manantial, 2007. p. 39-63. 
TELLO, C. La enseñanza de la Política Educativa y la formación de investigadores en el campo. Entre las matrices históricas y la episteme de época. Revista de Educação Pública, Cuiabá, v. 24, n. 55, p. 125-151, jan./abr. 2015.

TELLO, C; MAINARDES, J. Revistando o enfoque das epistemologias da política educacional. Práxis Educativa, Ponta Grossa, v. 10, n. 1, p. 153-178, jan./jun. 2015.

VIEIRA, S. L. Educação Básica: política e gestão da escola. Brasília: Liber Livro, 2009.

VIEIRA, S. L.; AlBUQUerQUE, M. G. M. Política e planejamento educacional. Fortaleza: Demócrito Rocha, 2001.

VIEIRA, S. L.; FARIAS, I. M. S. de. Política educacional no Brasil: introdução histórica. Brasília: Líber Livro, 2007.

VISACOVSKY， N. ¿Cómo enseñar política educativa desde un bordaje interdisciplinar? In: ENCUENTRO LATINOAMERICANO DE PROFESSORES DE POLÍTICA EDUCATIVA, 1., 2015, Guarulhos-SP. Anais... Guarulhos-SP: UNIFESP, 2015. p. 1-12.

WITTMANN, L. C.; GRACINDO, R. V. (Coords.). O estado da arte em política e gestão da educação no Brasil: 1991 a 1997. Brasília: ANPAE; Campinas, SP: Autores Associados, 2001.

JEFFERSON MAINARDES é licenciado em Pedagogia (UEPG), Mestre em Educação (Unicamp) e Doutor (Institute of Education, University of London). É professor associado de Departamento de Educação da Universidade Estadual de Ponta Grossa (UEPG). Bolsista de Produtividade em Pesquisa (CNPq). Vicediretor da Red de Estudios Teóricos y Epistemológicos en Política Educativa (ReLePe).E-mail: jefferson.m@uol.com.br

SILVANA STREMEL é licenciada em Pedagogia (UEPG), Mestre em Educação e Doutora em Educação (UEPG). É professora do Departamento de Educação da Universidade Tecnológica Federal (UTFPR). E-mail: silvanastremel@gmail.com

GREGORY LUIS ROLIM ROSA é licenciado em Pedagogia (UEPG) e Mestrando em Educação (UFPR), Bolsista da Capes. E-mail: rolimg7@gmail.com 